\title{
EVALUATION OF INNERVATION IN CLEFT AFFECTED ORAL MUCOSA
}

\author{
Olga Rimdenoka, Māra Pilmane \\ Institute of Anatomy and Anthropology, Riga Stradiņš University, Riga, Latvia
}

\begin{abstract}
Orofacial clefts are one of the most common pathologies present at birth. The aim of the study was to evaluate the presence of PGP 9.5, substance P, VIP, CGRP, myelin and NFG in cleft affected mucosa of alveolar process, soft and hard palate, vomer and lip.
\end{abstract}

Methods. Orofacial cleft affected mucosa tissue samples were obtained during surgical cleft correction from 21 children aged from 2 months to 9 years and 10 months. Prepared tissue sections were stained by immunohistochemistry for PGP 9.5, substance P, VIP, CGRP, myelin and NGF. The intensity of staining was graded semiquantitatively.

Results. Mostly moderate number and numerous PGP 9.5, substance P, VIP, CGRP, myelin and NGF-containing nerve fibres and nerve fibre bundles and CGRP and NGF positive keratinocytes were detected. The most immunoreactive for PGP 9.5, myelin and NGF were nerve fibres, nerve fibre bundles and keratinocytes in lip mucosa tissue samples. Typically, PGP 9.5-containing nerve fibres were detected in subepithelium close to basal lamina, near blood vessels; thin PGP 9.5 positive nerve fibres were also observed between keratinocytes. Immunoreactivity of CGRP was higher than of substance P in nerve fibres and nerve fibre bundles. Statistically significant positive correlation was observed between all markers in subepithelium of all tissue samples.

Conclusions. The proved statistically significant strong inter-correlation and the number of general neuropeptide-containing innervation (PGP 9.5), sensory nerves (CGRP and substance P), and parasympathetic nerves (VIP) is similar in orofacial cleft affected oral mucosa to such described in scientific literature healthy oral mucosa, except the alveolar process covering mucosa where the above innervation varies.

Very strong and strong statistically significant positive correlations between the number of PGP 9.5, substance P, CGRP and VIP positive structures on the one hand, and NGF and myelin, on the other hand, indicate a 
connection between quality markers and common neuropeptide-containing, sensory and parasympathetic innervation in cleft affected oral tissue.

The number of PGP 9.5, NGF and myelin immunoreactive neuronal structures in lip mucosa is higher than in the alveolar process, soft and hard palate and vomer mucosa, suggesting the significance of qualitative common innervation in this organ even in the cleft affected case.

Keywords: orofacial cleft; innervation; oral mucosa

\section{INTRODUCTION}

Orofacial clefts are determined by a multifactorial model of inheritance in which the interaction of genetic and environmental risk factors results in one of the most common pathologies presented at birth. Depending on the population, it affects 1 in 300-2500 children. In the European population, the prevalence of the pathology is 1 in 700 live births [1].

Innervation plays an essential role in the development of various orofacial structures during embryogenesis, and neuropeptides are involved not only in neuronal signalling but also in cell proliferation, migration and angiogenesis. Therefore, defects in innervation and distribution of neuropeptides can partially lead to cleft palate and lip formation $[2,3]$. Moreover, only limited research has been done about the different most common neuronal system subdivision neuropeptides and quality markers.

Protein gene product 9.5 (PGP 9.5) is a member of the ubiquitin hydrolase family of proteins [4]. It is a highly specific pan-neuronal marker which stains myelinated and unmyelinated nerve fibres showing the general innervation pattern of the tissue $[5,6]$. It is also a marker for neuroendocrine cells [7]. Previous research has revealed that the increase of PGP 9.5 immunoreactive nerve fibres in lamina propria might be associated with different oral pathologies. So, in oral lichen planus affected oral mucosa, an increased number of PGP 9.5-containing nerve fibres near lamina propria has been found, suggesting the neuroinflammatory process [6]. Not only the increased number of PGP 9.5-containing, but also substance $P$ and CGRP positive nerve fibres have been detected in palatal mucosa of sleep apnoics, which signalise neurogenic lesion [8].

Substance $\mathrm{P}$ is an 11 amino acids-containing neuropeptide, which provides nociception and pain signalling. Therefore, it indicates sensory innervation [9, 10]. Substance $P$ is synthesized by neurons and also by inflammatory cells [11], and it performs its function via the neurokinin 1 receptor [9]. Substance P was found to be strongly expressed in oral squamous cell carcinoma, confirming 
that increase in the levels of substance $\mathrm{P}$ can reduce apoptosis and lead to cell proliferation [12].

Vasoactive intestinal peptide (VIP) is a 28 -amino acid parasympathetic neurotransmitter. Beside neurons, it is also produced by immune cells [13]. It functions through the specific G-protein-coupled receptors $\mathrm{VPAC}_{1}$ and $\mathrm{VPAC}_{2}$, and shows the potent growth related actions that influence cell division and neuronal survival $[14,15]$.

Calcitonin gene related peptide (CGRP) is a 37 amino acid neuropeptide, which is expressed in sensory neurons, providing nociceptive transmission in both central and peripheral nervous systems and giving the opportunity to evaluate the sensory innervation of the tissue. It is frequently co-expressed with substance P. CGRP is also involved in maintenance of vascular homeostasis. Two types of CGRP receptors - $\mathrm{CGRP}_{1}$ and $\mathrm{CGRP}_{2}$ - have been described $[16,17]$, and CGRP has been found to participate in regenerative processes by increasing fibroblast motility and extracellular matrix synthesis [18].

Nerve growth factor (NGF) is neurotrophin, which consists of 118 amino acids; it is produced by immune and nerve cells, keratinocytes, melanocytes, smooth muscle cells, fibroblasts and Schwann cells [19]. NGF plays an important role in survival, growth and maintenance of neurons in the mammalian nervous system, performing functions through two different receptors, TrkA and p75 [20,21]. NGF has been found to play a role in oral epithelial wound healing by participating in tissue remodelation, cellular proliferation, restitution, up-regulation of anti-apoptotic proteins and inflammation [22].

Myelin is a multilayered membrane ensheathing axons; therefore, it gives the opportunity to detect myelinated nerve fibres [23]. However, there is practically no research about the distribution of these fibres in cleft affected tissue.

On the basis of the above mentioned, the aim of this study was to evaluate the appearance and distribution of PGP 9.5, substance P, VIP, CGRP, myelin and NFG positive neuronal structures in cleft affected mucosa of alveolar process, soft and hard palate, vomer and lip.

\section{MATERIALS AND METHODS}

Mucosa tissue samples from lip (7), alveolar process (7), vomer (1), soft palate (3), hard palate (2) and from the border between soft and hard palate (1) were obtained during surgical cleft correction in the Cleft Lip and Palate Centre at the Institute of Stomatology of Riga Stradiņš University from 21 children with nonsyndromic orofacial clefts. Tissue samples were taken from children aged from 2 months to 9 years and 10 months (14 boys and 7 girls). Seven children 
had bilateral orofacial cleft, while 14 were diagnosed with unilateral orofacial cleft (Table 1).

Table 1. Diagnosis, sex and age of the patients.

\begin{tabular}{|c|c|c|c|c|}
\hline Patient & Sex & Age & Diagnosis & Tissue \\
\hline 1 & Boy & 9 years 10 months & Cheilognathouranoschisis bilateralis & \multirow{7}{*}{$\begin{array}{c}\text { Alveolar } \\
\text { process mucosa }\end{array}$} \\
\hline 2 & Boy & 9 years 3 months & Cheilognathouranoschisis bilateralis & \\
\hline 3 & Boy & 8 years 11 months & Cheilognathouranoschisis bilateralis & \\
\hline 4 & Boy & 8 years 5 months & Cheilognathouranoschisis bilateralis & \\
\hline 5 & Girl & 9 years & Cheilognathouranoschisis bilateralis & \\
\hline 6 & Boy & 8 years 5 months & Cheilognathouranoschisis sinistra & \\
\hline 7 & Girl & 8 years 5 months & Cheilognathouranoschisis sinistra & \\
\hline 8 & Boy & 3 years 7 months & Cheilognathouranoschisis sinistra & \multirow{2}{*}{$\begin{array}{c}\text { Hard palate } \\
\text { mucosa }\end{array}$} \\
\hline 9 & Girl & 3 years & $\begin{array}{c}\text { Cheilognathouranoschisis } \\
\text { dextra }\end{array}$ & \\
\hline 10 & Boy & 9 months & Cheilognathouranoschisis bilateralis & \multirow{3}{*}{$\begin{array}{c}\text { Soft palate } \\
\text { mucosa }\end{array}$} \\
\hline 11 & Boy & 10 months & $\begin{array}{c}\text { Cheilognathouranoschisis } \\
\text { sinistra }\end{array}$ & \\
\hline 12 & Girl & 8 months & $\begin{array}{c}\text { Cheilognathouranoschisis } \\
\text { sinistra }\end{array}$ & \\
\hline 13 & Girl & 9 months & Cheilognathouranoschisis sinistra & $\begin{array}{c}\text { Mucosa } \\
\text { from border } \\
\text { between soft } \\
\text { and hard palate }\end{array}$ \\
\hline 14 & Boy & 9 months & $\begin{array}{c}\text { Cheilognathouranoschisis } \\
\text { dextra }\end{array}$ & Vomer mucosa \\
\hline 15 & Boy & 2 months & Cheilognathouranoschisis bilateralis & \multirow{7}{*}{ Lip mucosa } \\
\hline 16 & Boy & 5 months & Cheilognathouranoschisis sinistra & \\
\hline 17 & Boy & 4 months & Cheilognathouranoschisis sinistra & \\
\hline 18 & Boy & 4 months & Cheilognathouranoschisis sinistra & \\
\hline 19 & Girl & 6 months & Cheilognathouranoschisis sinistra & \\
\hline 20 & Girl & 4 months & Cheilognathouranoschisis sinistra & \\
\hline 21 & Boy & 3 months & $\begin{array}{c}\text { Cheilognathouranoschisis } \\
\text { dextra }\end{array}$ & \\
\hline
\end{tabular}

The study was performed in accordance with the 1964 Declaration of Helsinki. After written informed consent from the parents of all the 21 patients was received, tissue samples were obtained intraoperatively. The study was 
approved by the Ethics Committee at Riga Stradiņš University (22.05.2003; 17.01.2013; 5/25.06.2018).

Alveolar process, soft and hard palate, vomer and lip mucosa tissue samples were fixed in Stefanini's solution [24]. The solution was made of $20 \mathrm{~g}$ paraformaldehyde, $150 \mathrm{ml}$ of picric acid, $425 \mathrm{ml}$ of Shorensen`s phosphate buffer ( $\mathrm{pH} 7.2$ ) and $425 \mathrm{ml}$ of distilled water. Further, all tissue samples were dehydrated and embedded in paraffin.

PGP 9.5 (Lot number 439273A, obtained from rabbit, dilution 1:100, Invitrogen, USA), substance P (code sc-58591, obtained from mouse, dilution 1:100, Santa Cruz, USA), VIP (code sc-20727, obtained from rabbit, dilution 1:100, Santa Cruz, USA), CGRP (catalogue number 2030101401, lot number 281328, obtained from rabbit, dilution 1:100, Quartett Immuno-diagnostika, Germany), NGF (code ab6199, obtained from mouse, dilution 1:100, Abcam, UK), myelin (code 2233MME, obtained from mouse, dilution 1:20, Euro Diagnostica, Sweden) primary antibodies were used by biotin-streptavidin immunohistochemistry (IMH) [25]. Tissue samples were counterstained with haematoxylin to stain the nuclei blue. All antibodies we used in this study were tested for positive and negative control.

The intensity of immunostaining was graded semiquantitatively. Respectively, no positive structures in the visual field were labeled as 0; occasional positive structures in the visual field were labeled with $0 /+$; few positive structures in the visual field were labeled with + ; few to moderate number of positive structures in the visual field were labeled with $+/++$; moderate number of positive structures in the visual field were labeled with ++ ; moderate to numerous positive structures in the visual field were labeled with $++/+++$; numerous positive structures in the visual field were labeled with +++ ; numerous to abundant positive structures in the visual field were labeled with $+++/++++$; and abundance of positive structures in the visual field were labeled with ++++ [26].

The data processing was performed with SPSS software, version 22.0 (IBM Company, Chicago, IL, USA). Spearman's rank correlation coefficient was used, where $r=0-0.2$ was assumed as a very weak correlation, $r=0.2-0.4-$ a weak correlation, $r=0.4-0.6-$ a moderate correlation, $r=0.6-0.8-$ a strong correlation and $\mathrm{r}=0.8-1.0$ - a very strong correlation. The level of significance for the test was chosen as $5 \%$ ( $\mathrm{p}$-value $<0.05)$.

For visual illustration, Leica DC 300F digital camera was used. Image processing and analysis was performed by Image Pro Plus 6.0 software (Media Cybernetics, Silver Spring, Maryland, USA). 


\section{RESULTS}

PGP 9.5-containing nerve fibre bundles and nerve fibres typically were observed around blood vessels (Figure 1) and in lamina propria close to epithelium (Figure 2), also some thin nerve fibres were found between keratinocytes. Mainly, few to moderate number $(+/++)$ of PGP 9.5-containing nerve fibres were detected in mucosa of alveolar process. Few $(+)$ to abundant $(++++)$ but mostly moderate number $(++)$ of PGP 9.5-containing nerve fibres and nerve fibre bundles were found in mucosa of soft and hard palate and vomer. Mainly moderate to numerous $(++/+++)$ PGP 9.5 positive neuronal structures were observed in cleft affected lip mucosa tissue samples.

Commonly, a moderate number $(++)$ of substance P-containing nerve fibre bundles and nerve fibres were detected in lamina propria, also innervating sebaceous glands and near blood vessels (Figure 3). Few to moderate number $(+/++)$ of substance P positive nerve fibres were observed in subepithelial tissue of alveolar process mucosa. Mainly a moderate number $(++)$ of substance P immunoreactive neuronal structures was also found in soft and hard palate, vomer and lip mucosa tissue samples.

Commonly, VIP-containing nerve fibres and nerve fibre bundles were detected in the subepithelium (Figure 4) and in the wall of blood vessels (Figure 5). Few to moderate number $(+/++)$ of VIP immunoreactive nerve fibres were seen in lamina propria of alveolar process mucosa, while the subepithelium of soft and hard palate and vomer demonstrated mainly a moderate number $(++)$ of VIP positive neuronal structures. Mainly numerous $(+++)$ VIP-containing nerve fibres and nerve fibre bundles were observed in the subepithelium of lip.

Also, CGRP-containing nerve fibre bundles and separate nerve fibres were found in the subepithelium (Figure 6) and around the blood vessels. Moderate to numerous $(++/+++)$ CGRP positive nerve fibres and nerve fibre bundles were detected in lamina propria of soft and hard palate, vomer and alveolar process. The immunoreactivity for CGRP was detected in neuroendocrine cells of epithelium in alveolar process and lip mucosa. However, numerous $(+++)$ CGRP-containing nerve fibre bundles and nerve fibres were primarily seen in the subepithelium of lip; in soft and hard palate and vomer epithelium mostly a moderate number $(++)$ of CGRP positive cells were detected.

NGF-containing neuronal structures were displayed in the subepithelium (Figure 7), and NGF positive neuroendocrine cells appeared in the epithelium, typically located in the basal cell layer. Alveolar mucosa samples primarily contained few to moderate number $(+/++)$ of NGF positive nerve fibres and 
a moderate number $(++)$ of NGF immunoreactive cells in the epithelium. A moderate number $(++)$ of NGF-containing nerve fibres, nerve fibre bundles and neuroendocrine cells was also detected in soft and hard palate and vomer tissue samples, while mostly numerous $(+++)$ factor-containing neuronal structures were seen in lip mucosa.

A moderate number (++) of myelin ensheathed nerve fibres and nerve fibre bundles (Figure 8 ) occupied primarily the subepithelium of alveolar process, soft and hard palate and vomer mucosa. Numerous $(+++)$ myelin-containing nerve fibres and nerve fibre bundles were found mostly in the subepithelial tissue of lip mucosa.

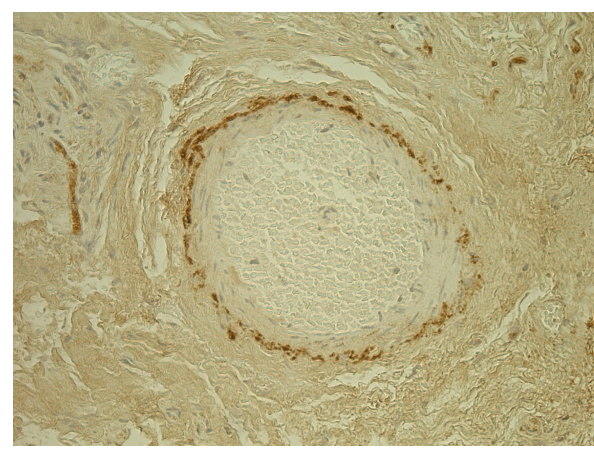

Figure 1. Numerous PGP 9.5-containing nerve fibres around a blood vessel in subepithelium of alveolar process mucosa in 9 years and 3 months old boy with bilateral orofacial cleft. PGP 9.5 IMH, x250.

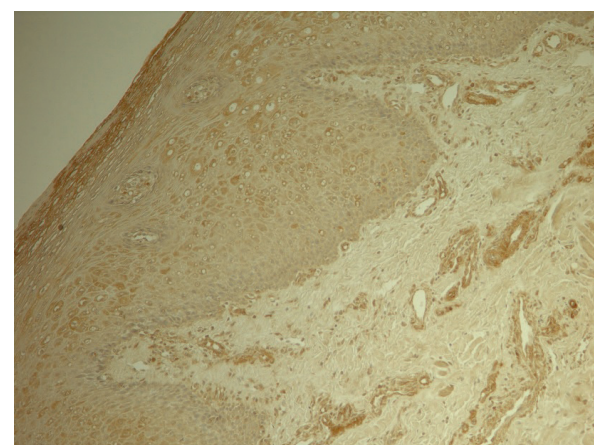

Figure 3. Moderate to numerous substance P-containing nerve fibres in lamina propria and nearby blood vessels in lip tissue samples of a 4-month-old boy with unilateral orofacial cleft. Substance P IMH, ×100.

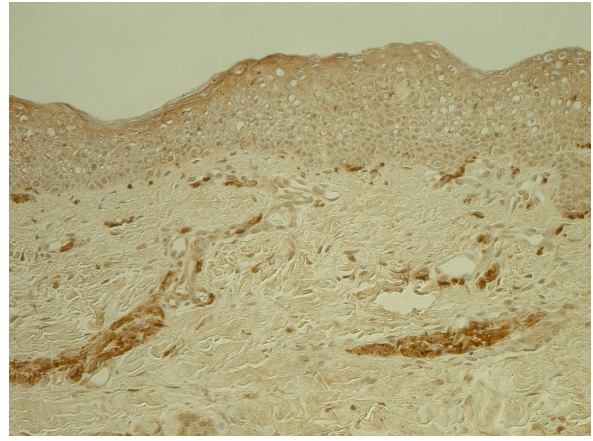

Figure 2. Moderate number of PGP 9.5 positive nerve fibres located close to basal lamina and nerve fibre bundles in subepithelium of lip mucosa in a 5-month-old boy with unilateral orofacial cleft. PGP $9.5 \mathrm{IMH}, \times 200$.

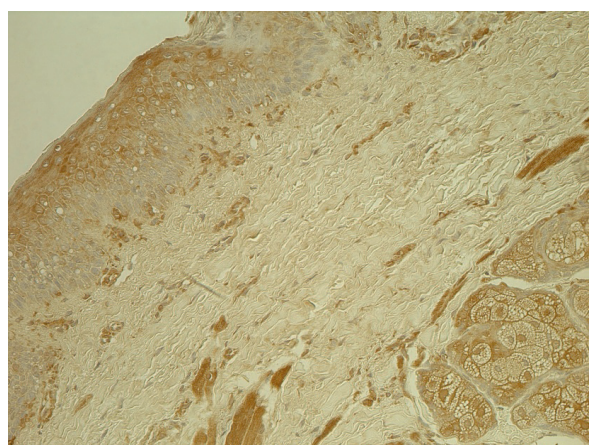

Figure 4. Moderate number of VIP-containing nerve fibres (located close to basal lamina) in the subepithelium on the border between soft and hard palate mucosa of a 9-monthold girl with unilateral orofacial cleft. VIP IMH, $\times 200$ 

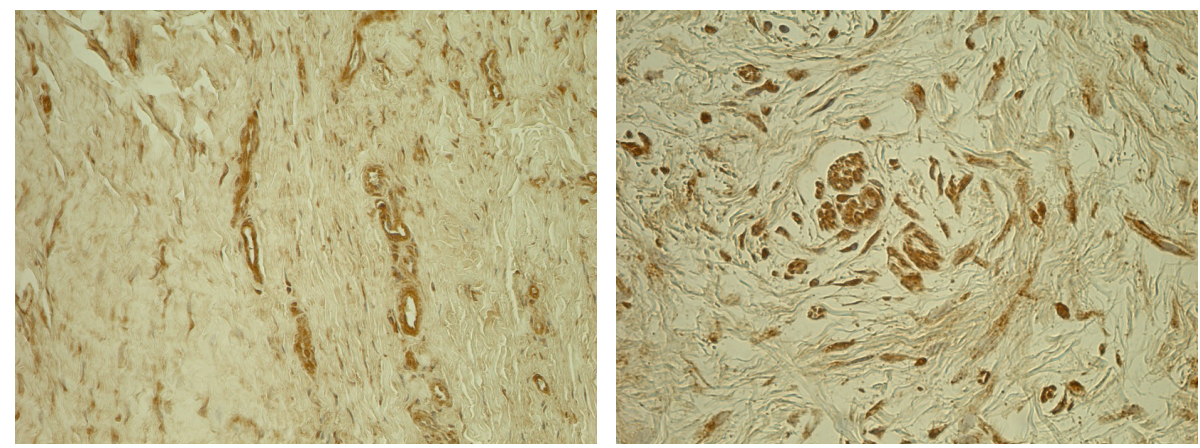

Figure 5. Numerous VIP-containing nerve fi- Figure 6. Moderate number of CGRP positive bres in the wall of blood vessels in the sube- nerve fibres in the subepithelium of hard palpithelium of lip mucosa in a 4-month-old girl ate mucosa of a 3-year-old girl with unilateral with unilateral orofacial cleft. VIP IMH, $\times 250$.. orofacial cleft. CGRP IMH, $\times 400$.
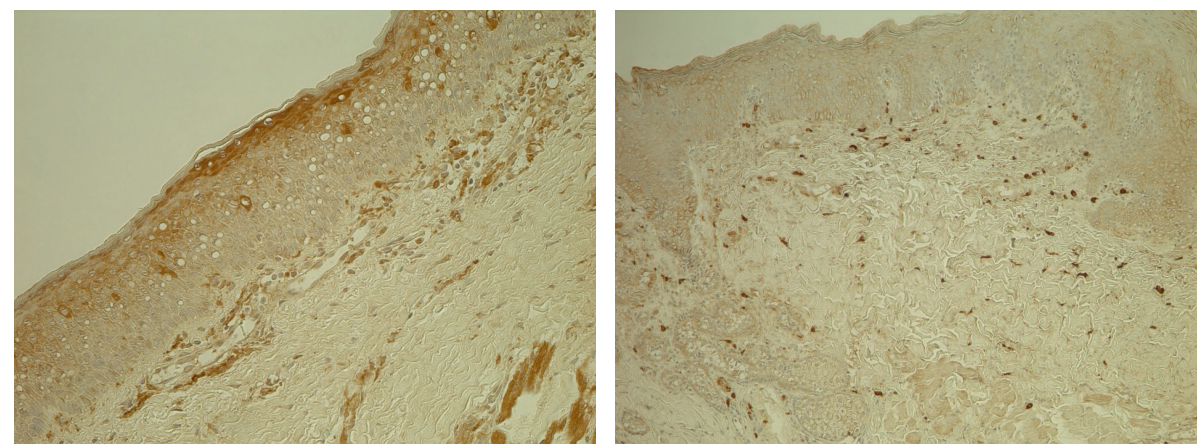

Figure 7. Moderate number of NGF-contain- Figure 8. Numerous myelin positive nerve ing nerve fibres seen in the subepithelium fibres in the subepithelium of lip mucosa in on the border between soft and hard palate a 6-month-old girl with unilateral orofacial mucosa of a 9-month-old girl with unilateral cleft. Myelin IMH, $\times 100$.

orofacial cleft. NGF IMH, $\times 200$.

Statistically significant positive correlations were found between the numbers of all the studied markers in the neuronal structures of subepithelial tissue (Table 2). Very strong statistically significant positive correlation was observed between the number of myelin and PGP 9.5, NGF and substance P, NGF and myelin. Strong statistically significant positive correlation was observed between NGF and PGP 9.5, NGF and CGRP, myelin and substance P, myelin and VIP, myelin and CGRP, substance P and CGRP, VIP and CGRP, substance $\mathrm{P}$ and VIP, PGP 9.5 and substance P. Moderate statistically significant correlation was detected between NGF and VIP, CGRP and PGP 9.5, VIP and PGP 9.5. 
Table 2. Spearman's rank correlations between PGP 9.5, substance P, VIP, CGRP, myelin and NGF.

\begin{tabular}{|c|c|c|c|c|c|}
\hline & PGP 9.5 & Substance P & VIP & CGRP & Myelin \\
\hline NGF & $\begin{array}{c}R=0.789 \\
P=0.00002\end{array}$ & $\begin{array}{c}R=0.828 \\
P=0\end{array}$ & $\begin{array}{c}R=0.595 \\
P=0.00445\end{array}$ & $\begin{aligned} R & =0.710 \\
P & =0.00031\end{aligned}$ & $\begin{array}{l}R=0.907 \\
P=0\end{array}$ \\
\hline Myelin & $\begin{array}{l}R=0.804 \\
P=0.00001\end{array}$ & $\begin{array}{c}R=0.757 \\
P=0.00007\end{array}$ & $\begin{array}{c}R=0.653 \\
P=0.00135\end{array}$ & $\begin{array}{c}R=0.718, \\
P=0.00025\end{array}$ & \\
\hline CGRP & $\begin{array}{c}R=0.460, \\
P=0.03580\end{array}$ & $\begin{array}{c}R=0.689, \\
P=0.00056\end{array}$ & $\begin{array}{c}R=0.623 \\
P=0.00254\end{array}$ & & \\
\hline VIP & $\begin{array}{c}R=0.599 \\
P=0.00415\end{array}$ & $\begin{aligned} R & =0.724 \\
P & =0.00021\end{aligned}$ & & \multicolumn{2}{|c|}{$\begin{array}{l}\text { Very strong statistically } \\
\text { significant positive correlation }\end{array}$} \\
\hline Substance $P$ & $\begin{array}{c}R=0.764 \\
P=0.00006\end{array}$ & & & \multicolumn{2}{|c|}{$\begin{array}{l}\text { Strong statistically significant } \\
\text { positive correlation }\end{array}$} \\
\hline & & & & \multicolumn{2}{|c|}{$\begin{array}{l}\text { Moderate statistically significant } \\
\text { positive correlation }\end{array}$} \\
\hline
\end{tabular}

\section{DISCUSSION}

Orofacial clefts cause a range of functional and cosmetic problems [27]. 70\% of all orofacial clefts are nonsyndromic clefts, which have complex aetiology with multiple genetic and environmental factors [28]. The pathogenesis of orofacial cleft development and the role of innervation of oral mucosa in it still is incompletely understood.

Very strong and strong statistically significant positive correlation between the studied markers - PGP 9.5, myelin, NGF, substance P, CGRP and VIP indicates a connection between quality markers and neuropeptides. There are no previous studies which show a correlation between expression of neuropeptides and quality markers in neuronal structures, making this study innovative and unique. Additionally, a strong statistically significant positive correlation was detected between all neuropeptides - CGRP and substance P, CGRP and VIP, substance P and VIP -, giving evidence of the distribution pattern of these sensory and parasympathetic neuropeptides in the cleft affected tissue. Coexistence of CGRP and substance P has been seen in nerve fibres in oral lichen planus affected mucosa and in nerve fibres innervating the palates of sleep apnoics and habitual snorers; therefore, our results have partially been proved by the data of other authors $[6,8]$.

Mainly moderate to numerous PGP 9.5 immunoreactive nerves were localized in our patients' lip tissue and in the boundary area of soft and hard palate; however, only few to moderate number of neuronal structures were seen in alveolar process mucosa. This corresponds to a study where PGP 9.5 positive nerve fibres were detected forming a dense network in lamina propria of 
healthy human lip and alveolar process mucosa [29]. Also, a rich supply of PGP 9.5-containing nerve fibres has been found in the boundary area of soft and hard palate in healthy rat oral mucosa [30]. Like in our study, PGP 9.5-containing nerve fibres have been detected in the wall of blood vessels in healthy human palate [29]. Therefore, it can be suggested that this is typical of oral mucosa, except the alveolar process, where the number of PGP 9.5-containing neuronal structures can vary.

Only few to moderate number of NGF-containing nerve fibres, nerve fibre bundles and neuroendocrine cells were observed in our patients' palate and alveolar process mucosa. NGF has been found to play a role in processes which are important in orofacial development - cell survival, cellular proliferation, restitution, up-regulation of anti-apoptotic proteins and remodellation [22]. Therefore, it can be suggested that the detected number of NGF-containing neuronal structures in our patients' mucosa could possibly be not enough to provide for the previously mentioned processes and partially play a role in cleft development.

Moderate to numerous CGRP positive neuronal structures were detected in lamina propria of soft and hard palate, vomer, alveolar process and lip mucosa. According to another study, numerous CGRP positive nerve fibres have also been found in the hard palate of a healthy rat [31]. Like in our study, healthy soft and hard palate mucosa of rat, cat and monkey showed CGRP immunoreactive neuronal structures in subepithelium and around blood vessels [32]. Therefore, we can suggest that the obtained number and localization of CGRPcontaining nerve fibres might be typical of oral mucosa. Soft and hard palate mucosa contained mainly moderate to numerous CGRP positive neuronal structures, while a moderate number of substance P-containing nerve fibres were observed in this localization. In another study, the boundary area of soft and hard palate of a healthy rat also demonstrated a higher number of CGRPcontaining nerve fibres than substance P-containing nerves [30]. Based on the above mentioned, we conclude that the described substance P and CGRP neuronal distribution pattern can be assumed to be typical of palate mucosa.

Few to moderate number of substance P-containing nerve fibres were found in our patients' mucosa, while another studies showed numerous substance $\mathrm{P}$ positive neuronal structures in the hard palate and alveolar process of a healthy rat $[31,33]$. Like in our study, substance P-containing nerve fibres have been detected near blood vessels in healthy human alveolar process mucosa [34]. Substance $\mathrm{P}$ was found to be strongly expressed in oral squamous cell carcinoma, assuming that an increase in the levels of substance $\mathrm{P}$ can reduce 
apoptosis and lead to cell proliferation [12]. Thus, we suggest that sensory nerves in cleft palate partially do not influence the cell proliferation and the programmed cell death in our patients.

Only few to moderate number of VIP positive neuronal structures were observed in alveolar process mucosa; a moderate number of nerves was found in the soft and hard palate and vomer mucosa of our patients. However, numerous VIP immunoreactive nerve fibres have been found in healthy human soft palate mucosa [35]. Similarly to our findings, VIP positive nerve fibres have been found in the wall of blood vessels in healthy human mucosa and in the subepithelium of healthy rat hard palate $[31,35]$. VIP is thought to have potent growth-related actions that influence cell division and neuronal survival [15]. It can be suggested that distribution of these parasympathetic nerve fibres partially does not make an impact on the action of VIP in cleft affected tissue.

A moderate number of myelin ensheathed neuronal structures was seen in alveolar process, soft and hard palate and vomer mucosa, while mostly numerous neuronal structures were found in lip mucosa. Commonly, this suggests the presence of myelinated nerves in cleft affected tissue without any specific changes in the quality of nerves. There is practically no previous research about the distribution of myelinated nerve fibres in orofacial cleft affected mucosa. Moreover, decreased number and degeneration of myelinated nerve fibres have been associated with other different oral pathologies. Compared to controls, the number of myelinated nerve fibres was found to be decreased in gingival mucosa of streptozocin-diabetic mice [36], while myelinated nerves showed degenerative changes in mucosa of obstructive sleep apnoea patients [37]. Therefore, it can be suggested, that cleft affected mucosa does not show just previously described properties of myelinated fibres degeneration.

\section{CONCLUSIONS}

The proved statistically significant strong inter-correlation and the number of general neuropeptide-containing innervation (PGP 9.5), sensory nerves (CGRP and substance P), and parasympathetic nerves (VIP) is similar in orofacial cleft affected oral mucosa to such of healthy oral mucosa described in scientific literature, except the alveolar process covering mucosa where the above innervation varies.

Very strong and strong statistically significant positive correlations between the number of PGP 9.5, substance P, CGRP and VIP positive structures on the one hand, and NGF and myelin, on the other hand, indicate the connection 
between the quality markers and common neuropeptide-containing, sensory and parasympathetic innervation in cleft affected oral tissue.

The number of PGP 9.5, NGF and myelin immunoreactive neuronal structures in lip mucosa is higher than in the alveolar process, soft and hard palate and vomer mucosa suggesting the significance of qualitative common innervation in this organ even in the cleft affected case.

\section{ACKNOWLEDGEMENTS}

This research was funded by Riga Stradiņš University, No. 5-1/106/2019 of 12.04.2019 "The elaboration of diagnostic prognostic factor algorithm of facial tissue complex regeneration for cleft patients in longitudinal aspect." Prof. I. Akota is highly acknowledged for providing of material.

\section{REFERENCES}

1. Kempa I., Ambrozaitytė L., Stavusis J., Akota I., Barkane B., Krumina A., Matulevičienè A., Utkus A., Kučinskas V., Lace B. (2014). Association of BMP4 polymorphisms with non-syndromic cleft lip with or without cleft palate and isolated cleft palate in Latvian and Lithuanian populations. Stomatologija, 16(3), 94-101. https://sbdmj.lsmuni.lt/143/143-03.pdf

2. Pagella P., Jiménez-Rojo L., Mitsiadis T.A. (2014). Roles of innervation in developing and regenerating orofacial tissues. Cell Mol Life Sci, 71(12), 2241-2251. https://doi.org/10.1007/s00018-013-1549-0

3. Słoniecka M., Le Roux S., Boman P., Byström B., Zhou Q., Danielson P. (2015). Expression Profiles of Neuropeptides, Neurotransmitters, and Their Receptors in Human Keratocytes In Vitro and In Situ. PLoS One, 10(7), e0134157. https:// doi.org/10.1371/journal.pone.0134157

4. Olar A., He D., Florentin D., Ding Y., Ayala G. (2014). Biologic Correlates and Significance of Axonogenesis in Prostate Cancer. Hum Pathol, 45(7), 13581364. https://doi.org/10.1016/j.humpath.2014.02.009

5. Sun Y., Zhu L., Huang X., Zhou C., Zhang X. (2014). Immunohistochemical Localization of Nerve Fibers in the Pseudocapsule of Fibroids. Eur J Histochem, 58(2), 2249. https://doi.org/10.4081/ejh.2014.2249

6. Chattipakorn S., Ittichaicharoen J., Rangdaeng S., Chattipakorn N. (2011). Changes in peripheral innervation and nociception in reticular type and erosive type of oral lichen planus. Indian J Dent Res, 22(5), 678-683. https://doi. org/10.4103/0970-9290.93456 
7. Tomita T. (2013). PGP 9.5 immunocytochemical staining for pancreatic endocrine tumors. Islets, 5(3), 122-128. https://doi.org/10.4161/isl.25351

8. Friberg D., Gazelius B., Hökfelt T., Nordlander B. (1997). Abnormal afferent nerve endings in the soft palatal mucosa of sleep apnoics and habitual snorers. Regul Pept, 71(1), 29-36. https://doi.org/10.1016/S0167-0115(97)01016-1

9. Fu H.D., Wang S., Ge B., Li L.Q., Zeng H.M., Shu Q.F., Zhou Y. (2018). Nerve growth factor and substance $\mathrm{P}$ may be involved in moist exposed burn ointment-mediated chronic refractory wound healing. Exp Ther Med, 16(3), 19871993. https://doi.org/10.3892/etm.2018.6390

10. Butler D.S.C., Ambite I., Nagy K., Cafaro C., Ahmed A., Nadeem A., Filenko N., Tran T.H., Andersson K.E., Wullt B., Puthia M., Svanborg C. (2018). Neuroepithelial control of mucosal inflammation in acute cystitis. Sci Rep, 8(1), 11015. https://doi.org/10.1038/s41598-018-28634-0

11. Gillespie E., Leeman S.E., Watts L.A., Coukos J.A., O’Brien M.J., Cerda S.R., Farraye F.A., Stucchi A.F., Becker J.M. (2011). Truncated neurokinin-1 receptor is increased in colonic epithelial cells from patients with colitis-associated cancer. Proc Natl Acad Sci USA, 108(42), 17420-17425. https://doi.org/10.1073/ pnas. 1114275108

12. Mehboob R., Tanvir I., Warraich R.A., Perveen S., Yasmeen S., Ahmad F.J. (2015). Role of neurotransmitter Substance P in progression of oral squamous cell carcinoma. Pathol Res Pract, 211(3), 203-207. https://doi.org/10.1016/j. prp.2014.09.016

13. Wang Y., Mei Y., Bao S., Xu L. (2007). Vasoactive intestinal polypeptide enhances oral tolerance by regulating both cellular and humoral immune responses. Clin Exp Immunol, 148(1), 178-187. https://doi. org/10.1111/j.1365-2249.2007.03322.x

14. Ekström J., Godoy T., Loy F., Riva A. (2014). Parasympathetic vasoactive intestinal peptide (VIP): a likely contributor to clozapine-induced sialorrhoea. Oral Dis, 20(3), e90-e96. https://doi.org/10.1111/odi.12139

15. Gressens P., Paindaveine B., Hill J.M., Brenneman D.E., Evrard P. (1997). Growth factor properties of VIP during early brain development. Whole embryo culture and in vivo studies. Ann N Y Acad Sci, 814, 152-160. https:// doi.org/10.1111/j.1749-6632.1997.tb46153.x

16. Granstein R.D., Wagner J.A., Stohl L.L., Ding W. (2015). Calcitonin GeneRelated Peptide: Key Regulator of Cutaneous Immunity. Acta Physiol (Oxf), 213(3), 586-594. https://doi.org/10.1111/apha.12442

17. Wrobel Goldberg S., Silberstein S.D. (2015). Targeting CGRP: A New Era for Migraine Treatment. CNS Drugs, 29(6), 443-452. https://doi.org/10.1007/ s40263-015-0253-Z

18. Chung A.M. (2018). Calcitonin gene-related peptide (CGRP): role in peripheral nerve regeneration. Rev Neurosci, 29(4), 369-376. https://doi.org/10.1515/ revneuro-2017-0060 
19. Aarão T.L.S., de Sousa J.R., Falcão A.S.C., Falcão L.F.M., Quaresma J.A.S. (2018). Nerve Growth Factor and Pathogenesis of Leprosy: Review and Update. Front Immunol, 9, 939. https://doi.org/10.3389/fimmu.2018.00939

20. Luo J., Yang Y., Zhang T., Su Z., Yu D., Lin Q., Chen H., Zhang Q., Xiang Q., Xue W., Ge R., Huang Y. (2018). Nasal delivery of nerve growth factor rescue hypogonadism by up-regulating $\mathrm{GnRH}$ and testosterone in aging male mice. EBioMedicine, 35, 295-306. https://doi.org/10.1016/j.ebiom.2018.08.021

21. Carrasco R.A., Singh J., Adams G.P. (2018). The relationship between gonadotropin releasing hormone and ovulation inducing factor/nerve growth factor receptors in the hypothalamus of the llama. Reprod Biol Endocrinol, 16(1), 83. https://doi.org/10.1186/s12958-018-0402-6

22. Schenck K., Schreurs O., Hayashi K., Helgeland K. (2017). The Role of Nerve Growth Factor (NGF) and Its Precursor Forms in Oral Wound Healing. Int J Mol Sci, 18(2). https://doi.org/10.3390/ijms 18020386

23. Monk K.R., Talbot W.S. (2009). Genetic dissection of myelinated axons in zebrafish. Curr Opin Neurobiol, 19(5), 486-490. https://doi.org/10.1016/j. conb.2009.08.006

24. Stefanini M., De Martino C., Zamboni L. (1967). Fixation of ejaculated spermatozoa for electron microscopy. Nature, 216(5111), 173-174. https://doi. org/10.1038/216173a0

25. Hsu S.M., Raine L., Fanger H. (1981). The use of antiavidin antibody and avidin-biotin-peroxidase complex in immunoperoxidase technics. Am J Clin Pathol, 75(6), 816-821. https://doi.org/10.1093/ajcp/75.6.816

26. Pilmane M., Luts A., Sundler F. (1995). Changes in neuroendocrine elements in bronchial mucosa in chronic lung disease in adults. Thorax, 50(5), 551-554. https://doi.org/10.1136/thx.50.5.551

27. Neogi S.B., Singh S., Pallepogula D.R., Pant H., Kolli S.R., Bharti P., Datta V., Gosla S.R., Bonanthaya K., Ness A., Kinra S., Doyle P., Gudlavalleti V.S.M. (2017). Risk factors for orofacial clefts in India: A case-control study. Birth Defects Res, 109(16), 1284-1291. https://doi.org/10.1002/bdr2.1073

28. Carlson J.C., Taub M.A., Feingold E., Beaty T.H., Murray J.C., Marazita M.L., Leslie E.J. (2017). Identifying Genetic Sources of Phenotypic Heterogeneity in Orofacial Clefts by Targeted Sequencing. Birth Defects Res, 109(13), 10301038. https://doi.org/10.1002/bdr2.23605

29. Hilliges M., Astbäck J., Wang L., Arvidson K., Johansson O. (1996). Protein gene product 9.5-immunoreactive nerves and cells in human oral mucosa. Anat Rec, 245(4), 621-632. https://doi.org/10.1002/ (SICI)1097-0185(199608)245:4<621::AID-AR2>3.0.CO;2-R

30. Kato J., Uddman R., Sundler F., Kurisu K. (1998). Immunohistochemical study of the innervation of the boundary area of the hard and soft palates of the rat. Acta Anat (Basel), 163(2), 92-98. https://doi.org/10.1159/000046488 
31. Itotagawa T. (1990). Immunohistochemical studies on the peptidergic nerve distribution in hard palate mucosa and gingiva of the rat. Osaka Daigaku Shigaku Zasshi, 35(1), 78-92. https://www.ncbi.nlm.nih.gov/pubmed/1725789

32. Rodrigo J., Polak J.M., Terenghi G., Cervantes C., Ghatei M.A., Mulderry P.K., Bloom S.R. (1985). Calcitonin gene-related peptide (CGRP)-immunoreactive sensory and motor nerves of the mammalian palate. Histochemistry, 82(1), 67-74. https://doi.org/10.1007/BF00502092

33. Kido M.A., Yamaza T., Goto T., Tanaka T. (1999). Immunocytochemical localization of substance $P$ neurokinin-1 receptors in rat gingival tissue. Cell Tissue Res, 297(2), 213-222. https://doi.org/10.1007/s004410051349

34. Bartold P.M., Kylstra A., Lawson R. (1994). Substance P: an immunohistochemical and biochemical study in human gingival tissues. A role for neurogenic inflammation? J Periodontol, 65(12), 1113-1121. https://doi.org/10.1902/ jop.1994.65.12.1113

35. Hauser-Kronberger C.E., Hacker G.W., Sundler F., Thurner J., Albegger K. (1992). Distribution and co-localization of immunoreactive helospectin with vasoactive intestinal polypeptide and peptide histidine methionine in human nasal mucosa, soft palate and larynx. Eur Arch Otorhinolaryngol, 249(4), 201205. https://doi.org/10.1007/BF00178469

36. Fehér D., Gyorffi A., Fazekas A. (2001). Neurogenic inflammation of gingivomucosal tissue in streptozotocin-diabetic rat. Arch Physiol Biochem, 109(3), 230-233. https://doi.org/10.1076/apab.109.3.230.11597

37. Woodson B.T., Garancis J.C., Toohill R.J. (1991). Histopathologic changes in snoring and obstructive sleep apnea syndrome. Laryngoscope, 101(12 Pt 1), 1318-1322. https://doi.org/10.1002/lary.5541011211

\section{Address for correspondence:}

Olga Rimdenoka

Riga Stradiņš University

Institute of Anatomy and Anthropology

Kronvalda Boulevard 9, Riga, LV 1010, Latvia

E-mail: olga.rimdenoka@gmail.com

Prof. Māra Pilmane

Riga Stradiņš University

Institute of Anatomy and Anthropology

Kronvalda Boulevard 9, Riga, LV 1010, Latvia

E-mail: mara.pilmane@rsu.lv 